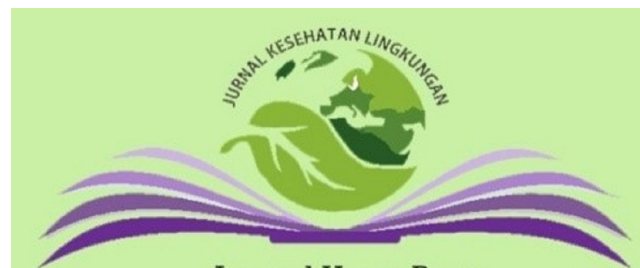

Journal Home Page:

https://e-journal.unair.ac.id/JKL

\section{Jurnal Kesehatan Lingkungan}

Vol. 13 No. 4

DOI: $10.20473 /$ jkl.v13i4.2021.227-240

ISSN: 1829 - 7285

E-ISSN: 2040 - 881X

\title{
DETERMINANTS OF PERSISTENT ORGANIC POLLUTANTS (POPS) LEVELS IN HUMAN SPECIMENS: A REVIEW
}

Farah Zahira ${ }^{1 *}$, Kusuma Scorpia Lestari ${ }^{1}$, Ahmad Zaharin Aris ${ }^{1,2}$

${ }^{1}$ Departement of Environmental Health, Faculty of Public Health, Universitas Airlangga, Surabaya 60115, Indonesia.

${ }^{2}$ Department of Environment, Faculty of Forestry and Environment, Universiti Putra Malaysia, 43400 UPM Serdang, Selangor, Malaysia.

\section{Corresponding Author:}

*) farah.zahira-2017@fkm.unair.ac.id

\section{Article Info}

Submitted

In reviewed

Accepted

: July 2021

: 9 July 2021

Available Online

16 September 2021

31 October 2021

Keywords : Persistent organic pollutants, POPs, Determinants, Risk factors, Human specimens

Published by Fakultas Kesehatan Masyarakat Universitas Airlangga

\begin{abstract}
Introduction: Numerous studies have been conducted regarding persistent organic pollutants (POPs) concentrations in human biological matrices such as blood, breast milk, urine, and hair that cause adverse health effects such as breast cancer, cardiovascular diseases, and type 2 diabetes. This study aimed to determine the POPs presence in human specimens in household settings. Discussion: A total of 28 articles were included in this study with the criteria published in 20162021, original research articles, free full text available, and studied at least one of the confounding variables of POPs levels in human specimens. The narrative method was selected to synthesize this study. Grouping articles with similar results was carried out to respond to research questions. This study discovered that age, dietary habits, BMI, sex, racelethnicity, smoking status, physical activities, residency, household dust, and industry emissions were associated with POPs levels in human specimens. Conclusion: This study concluded that each determinant could not affect the POPs levels in the human specimens on its own since those determinants are influenced by each other. Future research using systematic literature review and meta-analysis is therefore strongly advised.
\end{abstract}

\section{INTRODUCTION}

Persistent organic pollutants (POPs) are organic chemical substances widely distributed in the environment, involving soil (1), air (2), and water (3). They can remain intact for a long period since they have long half-lives and could persist for years or decades in the environment (4). For example, dichloro-diphenyltrichloroethane (DDT) is an organochlorine pesticide and remains intact in soil for 2-15 years (5). POPs can enter humans and animals through the food chain due to their lipophilic characteristics, causing them to bioaccumulate and biomagnify in the fatty tissues (6-8). Furthermore, in humans, they can also build up in breast milk (9), serum (10), plasma (11), urine (12), and hair (13) because of their high resistance to degradation (14).

POPs include organochlorine pesticides (OCPs), polychlorinated biphenyls (PCBs), polybrominated diphenyl ethers (PBDEs), and per- and polyfluoroalkyl substances (PFASs). OCPs are widely used in agriculture to control pests and vectors in some countries under the $\mathrm{WHO}$ recommendation (5), whereas $\mathrm{PCBs}$ are used in electrical equipment, PBDEs as fire-resistant in household goods, and per- and polyfluoroalkyl substances (PFASs) are used to coat various products (15). Based on the Stockholm Convention, the chemicals are listed into three categories; 1) Annex A determines chemicals that parties must take measures to eliminate the production and use; 2) Annex $B$ determines chemicals that parties must take measures to restrict; 3) Annex C determines chemicals whose unintentional release must be reduced (16).

OCPs are still used in some countries as vector control, following WHO recommendations. Approximately 4,400 metric tons of OCPs were used annually as vector control from 2000-2009 in Africa, America, Eastern Mediterranean, Europe, South East Asia, and Western Pacific (17). More than 1.3 million tons of $P C B$ s have been produced globally to this day (18). The total production of PBDEs was approximately 1.5 million tons from 1970 to 2005 (19).

POPs may contaminate the environment due to their persistent characteristic and spread widely to the areas where they have never been used. The POPs 
concentration was surprisingly observed in the Arctic, although it had been banned in the USA and Canada for a significant period. Precipitated pollutants persist in the environment for a considerably long period since the temperature does not allow them to break down easily. The incident of infamous POPs contamination occurred in The Great Lakes, which are the largest fresh surface water system in the earth and located in the United States. They are not only used as a source of drinking water and energy but also for agricultural, industrial, and recreational activities. However, these lakes were greatly exposed to POPs through waste sites, runoffs, and the atmosphere, endangering human health and wildlife, especially fish. As a result, the POPs blood levels in residents who consumed contaminated fish from the Great Lakes escalated. Due to these incidents, the United States and Canada agreed to reduce and monitor the POPs levels in the Great Lakes from 1972 to 2007 (20).

Data regarding POPs poisoning in humans is generally unavailable since these pollutants tend to cause chronic health effects. POPs presence in any human specimens has been known to cause human health risks, such as type 2 diabetes and gestational diabetes mellitus (21-23), breast cancer (24-25), and cardiovascular diseases (26-27). It is also well known that POPs are considered endocrine-disrupting chemicals (EDCs). They can also disrupt ovarian functions and women's reproductive system in low concentrations (28). They are also harmful to infants and children because POPs can be found in mothers' breast milk. Exposure to POPs through a mother's breast milk may develop long-term damages to the infant, such the growth and development (29), irreversible changes in the nervous system (30), increased risk of ADHD (31) and disrupted thyroid homeostasis (32). Prenatal exposure to POPs may cause higher birth weight (33), obesity during childhood (34), and adverse effects on neurodevelopment (35).

This study aims to determine the confounding factors for POPs levels in human specimens. The literature used in this study were research articles about POPs levels in human specimens and their risk factors. This study focused on POPs that are present in especially in household settings, and excluded studies that were conducted in an agricultural area where OCPs were or are still extensively used.

\section{DISCUSSION}

Although POPs have been prohibited, they are still present in the environment and human specimens due to the biomagnification and bioaccumulation process. The POPs that were released into the environment were accumulated in the organism's tissues. Subsequently, they moved to the higher trophic, where the biomagnification process occurred. Once they enter human bodies through food, they will be distributed inside, and the metabolism or the biotransformation process occurs. They may be metabolized into more toxic compounds than the parent molecule in endocrine organs (28).

Table 1. POPs classification in the Stockholm Convention

\begin{tabular}{|c|c|}
\hline Class & POPs \\
\hline A & $\begin{array}{l}\text { Pesticides: aldrin, chlordane, chlordecone, dicofol, eldrin, } \\
\text { heptachlor, hexachlorobenzene, alpha-hexachlorocyclohexane, } \\
\text { beta-hexachlorocyclohexane, lindane, mirex, penta- } \\
\text { chlorobenzene, pentachlorophenol, toxaphene Industrial } \\
\text { chemicals: decabromodiphenyl ether, hexabromobiphenyl, } \\
\text { hexabromocyclododecane, hexabromobiphenyl ether, } \\
\text { hexachlorobenzene, hexachlorobutadiene, pentachlorobenzene, } \\
\text { polychlorinated biphenyls, polychlorinated naphthalenes, } \\
\text { perfluorooctanoic acid, tetrabromodiphenyl ether, } \\
\text { pentabromodiphenyl ether }\end{array}$ \\
\hline B & $\begin{array}{l}\text { Pesticide: DDT } \\
\text { Industrial chemicals: perfluorooctane sufonic acid }\end{array}$ \\
\hline $\mathrm{C}$ & $\begin{array}{l}\text { Hexachlorobenzene, hexachlorobutadiene, pentachlorobenzene, } \\
\text { polychlorinated dibenzo-p-dioxins, polychlorinated } \\
\text { dibenzofurans, polychlorinated biphenyls, and polychlorinated } \\
\text { naphthalenes }\end{array}$ \\
\hline
\end{tabular}

There have been various studies on body burdens of POPs, such as in blood (serum or plasma), breast milk, urine, and hair. POPs presence in breast milk has been predominantly studied since it better represents POPs exposure to infants (36). Hair is also a feasible sample to be collected, transported, and stored, and it can be used to detect POPs because contaminants in the blood are carried from the bloodstream to the hair follicle. Furthermore, it is a non-invasive matrix and presents $1-9 \%$ lipids, which is considered high (37).

Scientific research articles on several databases on the internet, namely Pubmed, Science Direct, Research Gate, DOAJ, and Garuda, were referred to for this study. The selected studies include journal articles published within five years (2016-2021), discussed at least one confounding determinant related to human health, and incorporated POPs levels in the human specimens in its research.

The keywords used to find the articles in those databases were "persistent organic pollutants"; "organochlorine pesticides"; "milk"; "urine"; "blood"; "serum"; and "hair". The articles were then screened according to title, publication year, and abstract. Review articles and original research articles that did not provide sufficient answers to the research question were excluded. After a subsequent review, 28 articles 
were finally selected. The narrative method was used to synthesize this study. Grouping articles with similar results were carried out to answer the research questions, namely the risk factors that affect POPs levels in the human specimens. Research articles that match the criteria were then summarized in Table 2 .

Table 2. Summary of Literature Review from Selected Articles

\begin{tabular}{|c|c|c|c|c|c|}
\hline Author & Title & $\begin{array}{l}\text { Population } \\
\text { and Sample }\end{array}$ & Method & Findings & Conclusion \\
\hline $\begin{array}{l}\text { Chen MW, Santos HM, } \\
\text { Que DE, Gou YY, Tayo } \\
\text { LL, Hsu YC, et al (14) } \\
\text { Location: } \\
\text { Taiwan }\end{array}$ & $\begin{array}{l}\text { Association between } \\
\text { Organochlorine Pesticide } \\
\text { Levels in Breast Milk } \\
\text { and Their Effects on } \\
\text { Female Reproduction in a } \\
\text { Taiwanese Population }\end{array}$ & $\begin{array}{l}68 \text { breast milk } \\
\text { samples }\end{array}$ & - & $\begin{array}{l}\text { 1. Mothers aged more than } 31 \text { years had } \\
\text { significantly higher cis-CHL levels than the } \\
\text { mothers aged }<31 \text { years }(\mathrm{p}=0,043) \text {. } \\
\text { 2. Mothers with higher pre-pregnant BMI tend to } \\
\text { have lower levels of aldrin, DDD, endosulfan } \\
\text { II, and heptachlor } \\
\text { 3. There is a correlation between dietary habits } \\
\text { that consist of meat and dairy products and the } \\
\text { risk of having OCPs presence in human milk. }\end{array}$ & $\begin{array}{l}\text { Age, pre-pregnant BMI, } \\
\text { and dietary habits were } \\
\text { significantly associated } \\
\text { with several OCPs levels } \\
\text { in human milk. }\end{array}$ \\
\hline $\begin{array}{l}\text { Aerts R, Van Overmeire } \\
\text { I, Colles A, Andjelković } \\
\text { M, Malarvannan G, } \\
\text { Poma G, et al (9) } \\
\text { Location: Belgium }\end{array}$ & $\begin{array}{l}\text { Determinants of persistent } \\
\text { organic pollutant (POP) } \\
\text { concentrations in the } \\
\text { breast milk of a cross- } \\
\text { sectional sample of } \\
\text { primiparous mothers in }\end{array}$ & $\begin{array}{l}206 \text { human } \\
\text { milk samples } \\
\text { from } \\
\text { primiparous } \\
\text { mothers }\end{array}$ & $\begin{array}{l}\text { Cross- } \\
\text { sectional }\end{array}$ & $\begin{array}{l}\text { 1. BMI and age were correlated with high POPs } \\
\text { levels. } \\
\text { 2. Higher DDT and DDE levels were found in } \\
\text { mothers who live in rural residency, have } \\
\text { habits of consuming home-produced egg and } \\
\text { fish products }\end{array}$ & $\begin{array}{l}\text { There was a correlation } \\
\text { between maternal age, } \\
\text { BMI, residency, and } \\
\text { dietary habits with POPs } \\
\text { levels. }\end{array}$ \\
\hline
\end{tabular}

Du J, Gridneva Z, Gay A longitudinal study of 99 human MCL, Lai CT, Trengove pesticide residue levels in milk from 16 RD, Hartmann PE, et human milk from Western mothers al (48) Australia during 12 months of lactation

Location:

Australia
Witczak A, Pohoryło A, Endocrine-Disrupting Breast milk

Abdel-Gawad H. (67) Organochlorine Pesticides samples from in Human 96 mothers

Location: Poland
Breast Milk: Changes

during Lactation
Longitudinal There was no significant correlation between DDE There was no significant study levels and maternal age, parity, maternal BMI, and correlation between fat mass percentage. maternal age, parity, and maternal BMI

\section{Souza RC, Portella RB, Human milk}

Almeida PVNB, Pinto contamination by nine

$\mathrm{CO}$, Gubert P, Santos da organochlorine pesticide

Silva JD, et al (49) residues (OCPs)

\section{Location: Brazil}

Grešner P, Zieliński M, Environmental exposure Breast milk Ligocka D, Polańska to persistent organic samples $\mathrm{K}$, Wąsowicz W, pollutants measured in the from 110 Gromadzińska J (30) breast milk of lactating primiparous women from an urban area mothers

Location: Poland in central Poland

\section{Human milk}

from 34

mothers
1. A positive correlation was found between poultry

2. No correlation was found between maternal age and residency with DDT or $\mathrm{HCH}$ levels.

1. Mother's age and OCPs levels in breast milk was not significantly correlated with OCPs concentrations

2. Having a daily diet rich in milk and meat consumption were not significantly correlated with OCPs levels in breast milk

1. Total dl-PCB concentration was positively and There was a correlation negatively correlated with the mother's age between dl-PCB mothers aged under median value

3. The total WHO-TEQ for 29 POPs were significantly associated with the consumption frequency of fish and dairy products

mother's age

There was a correlation between
2. PCBs levels were significantly lower in concentration and the concentration of WHO-TEQ for 29 POPs detected and dietary habit

\begin{tabular}{|c|c|c|c|c|c|}
\hline $\begin{array}{l}\text { Fiedler H, Kallenborn } \\
\text { R, Boer J de, Sydnes } \\
\text { LK (82) } \\
\text { Location: } 42 \text { different } \\
\text { countries }\end{array}$ & $\begin{array}{l}\text { Regional occurrence of } \\
\text { perfluoroalkane substances } \\
\text { in human milk for the } \\
\text { global monitoring plan } \\
\text { under the Stockholm } \\
\text { Convention on Persistent } \\
\text { Organic Pollutants during } \\
\text { 2016-2019 }\end{array}$ & $\begin{array}{l}44 \text { breast milk } \\
\text { samples }\end{array}$ & - & $\begin{array}{l}\text { 1. PFOA was detected in all } 44 \text { samples. } \\
\text { 2. People in wealthier countries have slightly } \\
\text { higher PFOA levels } \\
\text { 3. There is a significant difference between } \\
\text { PFOS \& PFOA residue levels in European } \\
\text { and African countries and countries with high } \\
\text { income and low income. }\end{array}$ & $\begin{array}{l}\text { There was an association } \\
\text { between PFOS and } \\
\text { PFOA levels and the } \\
\text { country's income. }\end{array}$ \\
\hline $\begin{array}{l}\text { Schuhmacher M, Mari } \\
\text { M, Nadal M, Domingo } \\
\text { JL (44) } \\
\text { Location: Spain }\end{array}$ & $\begin{array}{l}\text { Concentrations of dioxins } \\
\text { and furans in breast milk } \\
\text { of women living near a } \\
\text { hazardous waste } \\
\text { incinerator in Catalonia, } \\
\text { Spain }\end{array}$ & $\begin{array}{l}20 \text { human milk } \\
\text { samples }\end{array}$ & - & $\begin{array}{l}\text { Dietary habits (fish, meat, oils, and fats) were } \\
\text { associated with the breast milk cluster. }\end{array}$ & $\begin{array}{l}\text { There was an association } \\
\text { between PCDD/Fs levels } \\
\text { and dietary habits. }\end{array}$ \\
\hline $\begin{array}{l}\text { Li C, Zhang L, Li J, } \\
\text { Min Y, Yang L, Zheng } \\
\text { M, et al (76) } \\
\text { Location: China }\end{array}$ & $\begin{array}{l}\text { Polychlorinated } \\
\text { naphthalenes in human } \\
\text { milk: Health risk } \\
\text { assessment to nursing } \\
\text { infants and source analysis }\end{array}$ & $\begin{array}{l}3790 \text { human } \\
\text { milk samples }\end{array}$ & - & $\begin{array}{l}\text { The activites of electronic waste recycling might } \\
\text { cause PCNs presence in breast milk. }\end{array}$ & $\begin{array}{l}\text { There was an association } \\
\text { between PCNs levels } \\
\text { in human milk and } \\
\text { emissions from } \\
\text { industries. }\end{array}$ \\
\hline
\end{tabular}




\begin{tabular}{|c|c|c|c|c|c|}
\hline Author & Title & $\begin{array}{l}\text { Population } \\
\text { and Sample }\end{array}$ & Method & Findings & Conclusion \\
\hline $\begin{array}{l}\text { Al Antary TM, Alawi } \\
\text { MA, Kiwan R, Haddad } \\
\text { NA (6) } \\
\text { Location: Jordan }\end{array}$ & $\begin{array}{l}\text { Organochlorine Pesticides } \\
\text { Residues in Human Breast } \\
\text { Milk from the Middle } \\
\text { Governorates in Jordan } \\
\text { in } 2013 / 2014\end{array}$ & $\begin{array}{l}100 \text { human } \\
\text { milk samples }\end{array}$ & - & $\begin{array}{l}\text { No associations were found between mothers' } \\
\text { demographic data (age, parity, dietary intake, and } \\
\text { body weight) }\end{array}$ & $\begin{array}{l}\text { There were no } \\
\text { associations between } \\
\text { OCPs levels and } \\
\text { mothers' characteristics }\end{array}$ \\
\hline $\begin{array}{l}\text { Lee YM, Shin JY, Kim } \\
\text { SA, Jacobs DR, Lee } \\
\text { DH (45) } \\
\text { Location: South Korea }\end{array}$ & $\begin{array}{l}\text { Can Habitual Exercise } \\
\text { Help Reduce Serum } \\
\text { Concentrations of } \\
\text { Lipophilic Chemical } \\
\text { Mixtures? Association } \\
\text { between Physical Activity } \\
\text { and Persistent Organic } \\
\text { Pollutants }\end{array}$ & $\begin{array}{l}\text { Serum from } \\
1.850 \text { healthy } \\
\text { adults }\end{array}$ & $\begin{array}{l}\text { Cross- } \\
\text { sectional }\end{array}$ & $\begin{array}{l}\text { 1. Decreasing } \beta \text {-HCH, DDE, DDT, and } \\
\text { heptachlor levels were found in individuals } \\
\text { with elevated physical activity duration ( } \mathrm{p}< \\
0,001,<0,001,<0,001,0,016 \text {, respectively } \\
\text { 2. No clear associations were observed between } \\
\text { PCBs levels in serum and physical activity }\end{array}$ & $\begin{array}{l}\text { There were associations } \\
\text { between physical } \\
\text { activities and OCPs } \\
\text { levels }\end{array}$ \\
\hline $\begin{array}{l}\text { Byrne S, Seguinot- } \\
\text { Medina S, Miller P, } \\
\text { Waghiyi V, Hippel FA } \\
\text { von, Buck CL, et al (79) } \\
\text { Location: Alaska, US } \\
\end{array}$ & $\begin{array}{l}\text { Exposure to } \\
\text { polybrominated diphenyl } \\
\text { ethers and perfluoroalkyl } \\
\text { substances in a remote } \\
\text { population of Alaska } \\
\text { Natives }\end{array}$ & $\begin{array}{l}\text { Serum from } 85 \\
\text { inland residents }\end{array}$ & - & $\begin{array}{l}\text { 1. There are statistical associations between } \\
\text { PBDEs concentration in serum and dust } \\
\text { 2. Fish consumption might contribute to PFAS } \\
\text { concentration in serum }\end{array}$ & $\begin{array}{l}\text { There are associations } \\
\text { between household } \\
\text { dust exposure to PBDE } \\
\text { serum concentration }\end{array}$ \\
\hline $\begin{array}{l}\text { Iglesias-González A, } \\
\text { Hardy EM, Appenzeller } \\
\text { BMR (40) } \\
\text { Location: France }\end{array}$ & $\begin{array}{l}\text { Cumulative exposure } \\
\text { to organic pollutants of } \\
\text { French children assessed } \\
\text { by hair analysis }\end{array}$ & $\begin{array}{l}\text { Hair samples } \\
\text { from } 142 \\
\text { French children }\end{array}$ & - & $\begin{array}{l}\text { 1. A significant difference was found between } \\
\text { PCP concentrations and genders } \\
\text { 2. Age and HCB levels were positively correlated } \\
\left(\mathrm{R}_{\text {spearman }}=0,25\right)\end{array}$ & $\begin{array}{l}\text { There might be } \\
\text { associations between } \\
\text { children's activities and } \\
\text { POPs concentration in } \\
\text { hair }\end{array}$ \\
\hline $\begin{array}{l}\text { Peng FJ, Emond C, } \\
\text { Hardy EM, Sauvageot } \\
\text { N, Alkerwi A, Lair ML, } \\
\text { et al (41) } \\
\text { Location: } \\
\text { Luxembourg }\end{array}$ & $\begin{array}{l}\text { Population-based } \\
\text { biomonitoring of exposure } \\
\text { to persistent and } \\
\text { non-persistent organic } \\
\text { pollutants in the Grand } \\
\text { Duchy of Luxembourg: } \\
\text { Results from hair analysis }\end{array}$ & $\begin{array}{l}\text { Hair samples } \\
\text { from } 497 \text { adults }\end{array}$ & - & $\begin{array}{l}\text { 1. Significantly higher concentrations of PCBs, } \\
\text { p,p'-DDT, and } \alpha \text {-Endosulfan were found } \\
\text { in females' hair }(\mathrm{p} \leq 0,047) \text {, while HCB } \\
\text { concentrations were higher in the male hair ( } \mathrm{p} \\
\leq 0,001) \\
\text { 2. Age was positively associated with } \gamma \text {-HCH and } \\
\text { HCB levels } \\
\text { 3. A positive relationship was found between } \\
\text { BMI and HCB concentrations }\end{array}$ & $\begin{array}{l}\text { Age, sex/gender, and } \\
\text { BMI had significant } \\
\text { associations with } \\
\text { specific POPs levels } \\
\text { in hair }\end{array}$ \\
\hline $\begin{array}{l}\text { Lee WC, Fisher M, } \\
\text { Davis K, Arbuckle TE, } \\
\text { Sinha SK (46) } \\
\text { Location: Canada }\end{array}$ & $\begin{array}{l}\text { Identification of chemical } \\
\text { mixtures to which } \\
\text { Canadian pregnant women } \\
\text { are exposed: The MIREC } \\
\text { Study }\end{array}$ & $\begin{array}{l}\text { Urine and } \\
\text { blood samples } \\
\text { from } 1744 \\
\text { participants }\end{array}$ & Cohort & $\begin{array}{l}\text { 1. Prenatal exposure to POPs was positively } \\
\text { associated with BMI } \geq 25 \mathrm{~kg} / \mathrm{m}^{2} \\
\text { 2. Women in their first pregnancy had } \\
\text { significantly higher POPs mean levels than } \\
\text { those with more parity } \\
\text { 3. There were significant differences in POPs } \\
\text { mean levels between smokers and non- } \\
\text { smokers } \\
\text { 4. Mother's level of education influenced } \\
\text { mixtures of organochlorine components } \\
\text { The regression model between maternal age } \\
\text { and organochlorine mixtures has a significant } \\
\text { slope }\end{array}$ & $\begin{array}{l}\text { There were associations } \\
\text { between POPs levels and } \\
\text { parity, smoking status, } \\
\text { income, education level, } \\
\text { maternal age, and BMI. }\end{array}$ \\
\hline $\begin{array}{l}\text { Lewin A, Arbuckle TE, } \\
\text { Fisher M, Liang CL, } \\
\text { Marro L, Davis K, et } \\
\text { al (47) } \\
\text { Location: Canada }\end{array}$ & $\begin{array}{l}\text { Univariate predictors of } \\
\text { maternal concentrations of } \\
\text { environmental chemicals: } \\
\text { The MIREC Study }\end{array}$ & $\begin{array}{l}\text { Blood and } \\
\text { urine samples } \\
\text { from } 1983 \\
\text { participants }\end{array}$ & Cohort & $\begin{array}{l}\text { 1. A relationship was found between maternal age } \\
\text { and POPs levels } \\
\text { 2. The geometric mean of PCBs and OCPs } \\
\text { concentrations were higher in nullipara than } \\
\text { primipara or multipara women, but they } \\
\text { weren't increased consistently with parity } \\
\text { 3. Some OCPs concentrations were higher in } \\
\text { non-smokers and former smokers than current } \\
\text { smokers } \\
\text { 4. Obese mothers have lower PCBs, } \\
\text { oxychlordane, and trans-nonachlor } \\
\text { concentration }\end{array}$ & $\begin{array}{l}\text { There were associations } \\
\text { between POPs levels } \\
\text { and maternal age, parity, } \\
\text { smoking status, BMI, } \\
\text { and household income }\end{array}$ \\
\hline $\begin{array}{l}\text { Vrijheid M, Fossati S, } \\
\text { Maitre L, Márquez S, } \\
\text { Roumeliotaki T, Agier } \\
\text { L, et al (56) }\end{array}$ & $\begin{array}{l}\text { Early-Life Environmental } \\
\text { Exposures and Childhood } \\
\text { Obesity: An Exposome- } \\
\text { Wide Approach }\end{array}$ & $\begin{array}{l}\text { Pregnancy } \\
\text { blood and urine } \\
\text { samples from } \\
1.301 \text { mother- } \\
\text { child pairs }\end{array}$ & Cohort & $\begin{array}{l}\text { There were associations between reduced BMI } \\
\text { and increased childhood DDE, HCB, PCBs, and } \\
\text { PBDE152 concentration in serum }\end{array}$ & $\begin{array}{l}\text { There were associations } \\
\text { between BMI and POPs } \\
\text { concentration }\end{array}$ \\
\hline $\begin{array}{l}\text { Wattigney WA, Irvin- } \\
\text { Barnwell E, Li Z, } \\
\text { Ragin-Wilson A (63) }\end{array}$ & $\begin{array}{l}\text { Biomonitoring of } \\
\text { mercury and persistent } \\
\text { organic pollutants in } \\
\text { Michigan urban anglers } \\
\text { and association with fish } \\
\text { consumption }\end{array}$ & $\begin{array}{l}\text { Blood and } \\
\text { urine samples } \\
\text { from } 287 \\
\text { adult shoreline } \\
\text { anglers }\end{array}$ & - & $\begin{array}{l}\text { 1. Elevated DDE and PCB levels was caused by } \\
\text { increasing age } \\
\text { 2. No significant relationship was found between } \\
\text { DDE and local fish consumption } \\
\text { 3. There was a significant association between } \\
\text { the habit of eating locally caught fish and PCB } \\
\text { levels ( } \mathrm{p}=0,0002) \\
\text { 4. Black people had higher PCBs concentrations } \\
\text { than white people }\end{array}$ & $\begin{array}{l}\text { There were associations } \\
\text { between age and DDE } \\
\text { levels } \\
\text { There were associations } \\
\text { between age, locally } \\
\text { caught fish consumption, } \\
\text { and race/ethnicity and } \\
\text { PCB levels }\end{array}$ \\
\hline
\end{tabular}




\begin{tabular}{|c|c|c|c|c|c|}
\hline Author & Title & $\begin{array}{l}\text { Population } \\
\text { and Sample }\end{array}$ & Method & Findings & Conclusion \\
\hline $\begin{array}{l}\text { Junqué E, Garí M, Arce } \\
\text { A, Torrent M, Sunyer J, } \\
\text { Grimalt JO (13) } \\
\text { Location: Spain }\end{array}$ & $\begin{array}{l}\text { Integrated assessment } \\
\text { of infant exposure } \\
\text { to persistent organic } \\
\text { pollutants and mercury via } \\
\text { dietary intake in a central } \\
\text { western Mediterranean site } \\
\text { (Menorca Island) }\end{array}$ & $\begin{array}{l}\text { Serum samples } \\
\text { from } 285 \\
\text { children } \\
\text { Hair samples } \\
\text { from } 302 \\
\text { children }\end{array}$ & Cohort & $\begin{array}{l}\text { 1. There was a direct significant association } \\
\text { between DDT levels and frequent consumption } \\
\text { of meat and fish } \\
\text { 2. Egg intake was associated to higher DDT } \\
\text { levels, but there was no statistical significance } \\
\text { 3. Consumption of fish and fruit was important } \\
\text { sources of organochlorines intake in } 4 \text { years } \\
\text { old children }\end{array}$ & $\begin{array}{l}\text { There was an association } \\
\text { between dietary habit } \\
\text { and 4,4'-DDT levels }\end{array}$ \\
\hline $\begin{array}{l}\text { Lan T, Liu B, Bao W, } \\
\text { Thorne PS (42) } \\
\text { Location: United States }\end{array}$ & $\begin{array}{l}\text { BMI modifies the } \\
\text { association between } \\
\text { dietary intake and serum } \\
\text { levels of PCBs }\end{array}$ & $\begin{array}{l}\text { Serum samples } \\
\text { from } 1.531 \\
\text { participants }\end{array}$ & $\begin{array}{c}\text { Cross- } \\
\text { sectional }\end{array}$ & 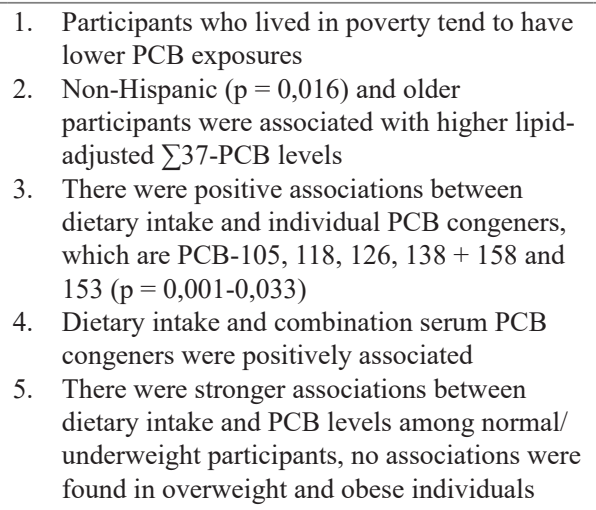 & $\begin{array}{l}\text { Age, household income, } \\
\text { race, dietary intake, and } \\
\text { BMI were associated } \\
\text { with PCB levels in blood } \\
\text { serum }\end{array}$ \\
\hline $\begin{array}{l}\text { Carvalho DFP, Meire } \\
\text { RO, Guimarães MT, } \\
\text { Pereira LAA, Braga } \\
\text { ALF, Bernardo RR, et } \\
\text { al (37) } \\
\text { Location: Brazil }\end{array}$ & $\begin{array}{l}\text { Determination of } \\
\text { Environmental Exposure } \\
\text { to DDT by Human Hair } \\
\text { Analysis in Santos and } \\
\text { Sao Vicente Estuary, Sao } \\
\text { Paulo, Brazil }\end{array}$ & $\begin{array}{l}\text { Hair samples } \\
\text { from } 122 \\
\text { participants }\end{array}$ & - & $\begin{array}{l}\text { There were neither associations nor significant } \\
\text { differences between DDT presence in hair among } \\
\text { the five studied areas }\end{array}$ & $\begin{array}{l}\text { There was no association } \\
\text { between DDT levels and } \\
\text { residency }\end{array}$ \\
\hline $\begin{array}{l}\text { Chang CJ, Terrell ML, } \\
\text { Marcus M, Marder } \\
\text { ME, Panuwet P, Ryan } \\
\text { PB (57) } \\
\text { Location: Michigan, } \\
\text { United States }\end{array}$ & $\begin{array}{l}\text { Serum concentrations of } \\
\text { polybrominated biphenyls } \\
\text { (PBBs), polychlorinated } \\
\text { biphenyls (PCBs) and } \\
\text { polybrominated diphenyl } \\
\text { ethers (PBDEs) in the } \\
\text { Michigan PBB Registry } \\
40 \text { years after the PBB } \\
\text { contamination incident }\end{array}$ & $\begin{array}{l}\text { Serum samples } \\
\text { from } 862 \\
\text { Michigan } \\
\text { residents }\end{array}$ & - & $\begin{array}{l}\text { 1. There was a } 3 \%, 4 \%, 1 \% \text { increase in PBB- } 153 \text {, } \\
\sum \mathrm{PCB}_{4} \text { and } \sum \mathrm{PBDE}_{3} \text { levels for a year increase } \\
\text { in age, respectively } \\
\text { 2. Men who were born before the incident tend } \\
\text { to have a significant increase }(127 \%) \text { of serum } \\
\text { levels than women } \\
\text { 3. Smokers had a significant decrease in PBB- } 152 \\
\text { levels ( } 47 \%) \text { than non-smokers } \\
\text { 4. No significant associations were found } \\
\text { between race, BMI, and dietary habit and POPs } \\
\text { levels }\end{array}$ & $\begin{array}{l}\text { Relationships were } \\
\text { found between age, sex, } \\
\text { smoking status, and } \\
\text { POPs levels, but they } \\
\text { were not found within } \\
\text { the race, BMI, and } \\
\text { dietary habits }\end{array}$ \\
\hline $\begin{array}{l}\text { Domazet SL, } \\
\text { Grøntved A, Jensen } \\
\text { TK, Wedderkopp N, } \\
\text { Andersen LB (58) } \\
\text { Location: Denmark }\end{array}$ & $\begin{array}{l}\text { Higher circulating plasma } \\
\text { polychlorinated biphenyls } \\
\text { (PCBs) in fit and lean } \\
\text { children: The European } \\
\text { youth heart study }\end{array}$ & $\begin{array}{l}\text { Blood samples } \\
\text { from } 509 \\
\text { children }\end{array}$ & Cohort & $\begin{array}{l}\text { 1. Children with higher fitness and lowest fat tend } \\
\text { to have higher } \sum \text { PCB levels }(\mathrm{p}<0,01) \\
\text { 2. No relationship was found between physical } \\
\text { activity and } \sum \text { PCB levels }\end{array}$ & $\begin{array}{l}\text { There was an association } \\
\text { between children's } \\
\text { fitness/fatness and } \\
\sum \text { PCB levels }\end{array}$ \\
\hline $\begin{array}{l}\text { Mansouri EH, Reggabi } \\
\text { M (11) } \\
\text { Location: Algiers }\end{array}$ & $\begin{array}{l}\text { Plasma concentrations } \\
\text { of chlorinated persistent } \\
\text { organic pollutants and } \\
\text { their predictors in the } \\
\text { general population of } \\
\text { Algiers, Algeria }\end{array}$ & $\begin{array}{l}\text { Plasma samples } \\
\text { from } 207 \text { adults }\end{array}$ & - & $\begin{array}{l}\text { 1. Women and adults with low educational levels } \\
\text { have higher } 4,4 \text { '-DDE concentrations } \\
\text { 2. Participants aged }>65 \text { years old have higher } \\
\text { POPs levels } \\
\text { 3. No significant difference was found } \\
\text { between POPs levels after adjustment of } \\
\text { fish consumption, smoking status, and } \\
\text { breastfeeding history }\end{array}$ & $\begin{array}{l}\text { Sex and educational } \\
\text { level were associated } \\
\text { with 4,4'-DDE levels } \\
\text { Age was associated with } \\
\text { POPs levels }\end{array}$ \\
\hline $\begin{array}{l}\text { Soleman SR, Fujitani T, } \\
\text { Fujii Y, Harada KH (62) } \\
\text { Location: Japan }\end{array}$ & $\begin{array}{l}\text { Levels of } \\
\text { Octachlorostyrene in } \\
\text { Mothers' Milk and } \\
\text { Potential Exposure Among } \\
\text { Infants in Sendai City, } \\
\text { Japan } 2021\end{array}$ & $\begin{array}{l}\text { Breast milk } \\
\text { samples from } \\
100 \text { mothers }\end{array}$ & $\begin{array}{l}\text { Cross- } \\
\text { sectional }\end{array}$ & $\begin{array}{l}\text { 1. A significant negative correlation was found } \\
\text { between octachlorostyrene (OCS) and lipid } \\
\text { content } \\
\text { 2. Stay-at-home mothers tend to have lower OCS } \\
\text { levels, suggesting there may be occupational } \\
\text { exposures }\end{array}$ & $\begin{array}{l}\text { There were relationships } \\
\text { between OCS levels } \\
\text { and lipid content, and } \\
\text { occupation }\end{array}$ \\
\hline $\begin{array}{l}\text { Güil-Oumrait N, Valvi } \\
\text { D, Garcia-Esteban R, } \\
\text { Guxens M, Sunyer J, } \\
\text { Torrent M, et al (59) }\end{array}$ & $\begin{array}{l}\text { Prenatal exposure } \\
\text { to persistent organic } \\
\text { pollutants and markers } \\
\text { of obesity and } \\
\text { cardiometabolic risk in } \\
\text { Spanish adolescents }\end{array}$ & $\begin{array}{l}\text { Blood samples } \\
\text { from } 379 \\
\text { children }\end{array}$ & Cohort & $\begin{array}{l}\text { 1. HCB levels and body fat were positively } \\
\text { associated } \\
\text { 2. No associations were found between p,p'-DDT } \\
\text { levels, and BMI }\end{array}$ & $\begin{array}{l}\text { There was an association } \\
\text { between body fat and } \\
\text { HCB levels, but not with } \\
\text { p,p'-DDT }\end{array}$ \\
\hline
\end{tabular}




\begin{tabular}{|c|c|c|c|c|c|}
\hline Author & Title & $\begin{array}{l}\text { Population } \\
\text { and Sample }\end{array}$ & Method & Findings & Conclusion \\
\hline $\begin{array}{l}\text { Schæbel LK, } \\
\text { Bonefeld-Jørgensen } \\
\text { EC, Vestergaard H, } \\
\text { Andersen S (64) } \\
\text { Location: Greenland }\end{array}$ & $\begin{array}{l}\text { The influence of persistent } \\
\text { organic pollutants in the } \\
\text { traditional Inuit diet on } \\
\text { markers of inflammation }\end{array}$ & $\begin{array}{l}\text { Blood samples } \\
\text { from } 535 \text { adults } \\
\text { aged } 50-69 \\
\text { years }\end{array}$ & - & $\begin{array}{l}\text { 1. Inuit participants have higher } \sum O C P, \sum P C B \text {, } \\
\text { and } \sum \text { PBDE serum levels than non-Inuit } \\
\text { participants } \\
\text { 2. Older participants have higher } \sum O C P, \sum P C B \text {, } \\
\text { and } \sum \text { PBDE levels } \\
\text { 3. Individuals who consume Greenlandic food } \\
\text { items the most have higher } \sum O C P, \sum P C B \text {, and } \\
\sum \text { PBDE levels }\end{array}$ & $\begin{array}{l}\text { There were associations } \\
\text { between POPs levels } \\
\text { and race, age, and } \\
\text { dietary habit }\end{array}$ \\
\hline $\begin{array}{l}\text { Moon HJ, Lim JE, Jee } \\
\text { SH (73) } \\
\text { Location: South Korea }\end{array}$ & $\begin{array}{l}\text { Association between } \\
\text { serum concentrations of } \\
\text { persistent organic } \\
\text { pollutants and smoking in } \\
\text { Koreans: A cross-sectional } \\
\text { study }\end{array}$ & $\begin{array}{l}\text { Serum samples } \\
\text { from } 401 \\
\text { participants }\end{array}$ & $\begin{array}{c}\text { Cross- } \\
\text { sectional }\end{array}$ & $\begin{array}{l}\text { 1. Women who ever smoke have significantly } \\
\text { higher PCBs levels than women who never } \\
\text { smoke } \\
\text { 2. There were positive associations between PCB } \\
157 \text { levels and men who ever smoke } \\
\text { 3. Individuals who smoke less than } 15 \text { cigarettes } \\
\text { per day are more likely to have high POPs } \\
\text { levels, compared to non-smokers }\end{array}$ & $\begin{array}{l}\text { There were positive } \\
\text { associations between } \\
\text { POPs levels and } \\
\text { smoking status }\end{array}$ \\
\hline
\end{tabular}

\section{Age}

Since POPs have lengthy biological half-lives, age is a critical variable that may influence POPs levels in human specimens $(11,38)$, and older individuals tend to have higher cumulative exposure to POPs (9). As indicated in Table 2, 13 journal articles discovered significant correlations and associations between age and specific POPs levels in human specimens.

Four journal articles discovered a correlation between age and POPs levels where cis-Chlordane, dichloro-diphenyl dichloro-ethylene (DDE), and PCB were found in breast milk, whereas older individuals have higher POPs levels $(9,14,30,39)$. Chlordane is a type of OCPs and is widely used as an insecticide. DDE is a breakdown product of DDT and has no particular use, and PCBs are a toxic chemical widely used in electrical products.

Two journal articles discovered that age and OCPs, namely $\mathrm{Y}$-hexachlorocyclohexane $(\mathrm{y}-\mathrm{HCH} /$ lindane) and hexachlorobenzene (HCB) levels in hair samples, were positively associated and that older study participants have higher OCPs levels in their hair than the younger ones (40-41). Four journal articles also discovered positive associations between age and POPs (PCBs, PBDE, PBB-153) levels in blood serum $(11,42-$ 44). Three journal articles discovered associations between age and POPs in both blood and urine samples (45-47). All these articles indicated that higher POPs levels were typically discovered in older individuals.

However, some studies failed to discover significant relationships between age and POPs levels in any human specimens, namely studies from Jordan (6), Australia (48), and Brazil (49). The authors of those studies cited a small sample size as the possible reason for the absence of a relationship between the two variables.

Among articles that discovered associations, POPs typically associated with increasing age are DDE,
$\mathrm{Y}-\mathrm{HCH}, \mathrm{HCB}$, and PCB. This suggests that OCPs are the type of POPs that are mostly present in human specimens due to their long half-lives and current use to this day, despite the prohibition. As a metabolite of DDT, DDE is still present in human specimens largely $(50) . \mathrm{Y}-\mathrm{HCH}$ or lindane is no longer produced in the United States but is still imported and used as insecticides in agriculture and treatment for lice and scabies (51). HCB is a fungicide that has been prohibited since the 1970s, but it might still be unintentionally produced as a byproduct of solvents and pesticides to this day, making its presence in the human specimens as a consequence (52).

A study suggested older people had higher PCBs levels because they grew up in an environment where $\mathrm{PCBs}$ levels were higher than today, causing them to be a reservoir for PCBs accumulation (42). PCBs were commercially used on electrical products due to their thermodynamic stability high quality before they were prohibited in the 1970s (53). They are still present today because spills, leaks, and releases from PCBscontaining equipment that was improperly disposed of are still discovered (54).

These positive associations between age and POPs levels are caused by the persistence, lipophilic, and bio-accumulative traits of POPs and the continuous exposure of POPs towards individuals $(48,55)$. However, it does not necessarily indicate that children and adolescents would always have lower POPs levels than adults because many other confounding factors could affect POPs levels in their biological matrices, such as residence, dietary habit, and direct exposure.

\section{Body Mass Index (BMI)}

Adipose tissue has a significant role in storing lipophilic chemicals such as POPs. BMI has invariably been associated with POPs levels. Previous studies have reported both positive and negative associations between these two variables. A total of six studies in 
Table 2 discovered significant negative correlations and associations between BMI and POPs levels.

A study from Taiwan discovered higher levels of aldrin, dichloro-diphenyl-dichloroethane (DDD), endosulfan, and heptachlor in the breast milk of mothers with lower BMI (14). Negative associations between PCBs and other POPs levels and BMI were also discovered in Canada, where individuals with $B M I \geq 25 \mathrm{~kg} /$ $\mathrm{m}^{2}$ have lower levels of such pollutants than individuals with $\mathrm{BMl}<25 \mathrm{~kg} / \mathrm{m}^{2}$ (46). Another study from Canada also discovered negative associations, where obese individuals have lower PCBs, oxychlordane, and transnonachlor (47). A longitudinal population-based study using cohorts from European countries consisting of the United Kingdom, France, Spain, Lithuania, Norway, and Greece discovered negative associations between organochlorine pollutant levels in the blood and lowered BMI (56). A study from the United States discovered a slight inverse association between PCB levels in serum and BMI (57). Another European study also discovered similar results, namely higher PCB levels in children with the lowest fat and higher fitness level (58). An inverse relationship between PCB levels and BMI was also discovered in a study from the United States (42).

On the other hand, some studies noticed positive associations between these two variables. A theory exists where higher BMl and more body fat signify more space for the pollutants, therefore higher POPs levels in fatter individuals. A study from Belgium discovered a positive association between BMI and POPs concentrations in breast milk, but since the BMI range was minor, the associations between $\mathrm{BMI}$ and POPs levels were insignificant (9). Positive associations between BMI and HCB levels were also discovered in a study from Luxembourg and Spain, increasing DDT levels in individuals with higher BMI Z-scores were also discovered in the study from Spain $(41,59)$

While nine studies found associations, four found neither associations nor correlations. A study conducted in China did not notice any significant correlation between $\mathrm{DDE}, \mathrm{HCB}$, and $\mathrm{HCH}$ concentrations in breast milk and BMI (39). A significant correlation between DDE concentrations in human milk and BMI was absent in a study conducted in Australia, but the small sample size, which is only 16 individuals, was cited as the probable cause (48).

Of the 13 articles that examined how BMI and fatness could have affected the POPs level, ten articles discovered negative associations, where individuals with higher BMI or fatness levels have lower POPs levels. A study claimed that even with a similar cumulative amount of exposure, individuals with higher BMI would still tend to have lower POPs levels in their specimens. The result was under the ratio between POPs concentrations and individual's body fat (60). Another study suggested that the negative associations were an effect of faster elimination and higher circulation of POPs from the adipose tissue in individuals with lower BMI than individuals with higher BMI (42). POPs dilution in elevating BMI was also suggested in previous studies that discovered inverse associations (57).

Lower POPs levels in the breast milk of individuals with higher BMI are caused by the different capacity and storage duration of adipocyte tissue subtype in each body part. This caused the distribution, metabolism, and excretion of POPs to be hard to predict (61). In crosssectional studies, the associations between BMI and POPs levels have been inconsistent, which might be linked to the age of the study participants, cohort effects (obesity epidemic), and period impacts (time following peak exposure) (57).

\section{Sex/Gender}

Sex or gender has not been thoroughly studied in research on POPs body burden. Gender-based studies regarding this topic are typically conducted to observe how POPs prenatal exposure causes different health impacts among children of both genders. This literature review study identified three studies that discovered associations between sex and POPs level in hair and serum samples.

The first study, conducted in Luxembourg, discovered significantly higher levels of DDT, $\alpha$-Endosulfan, and several PCBs in female hair, while $\mathrm{HCB}$ levels were higher in male hair. The difference was suggested to be caused by different exposure patterns between males and females (41). The second study in the United States discovered higher polybrominated biphenyl (PBB)-153 levels in serum. Occupational PBB exposure among men, since there were participants who worked and used to work as chemical workers, was cited as the probable cause (57). Occupational POPs exposure was also observed in a previous study conducted in Japan (62). PBBs were widely used as a fire retardant in plastics and coatings, and although it is no longer used in the United States, it is still limitedly used in electronic products in Europe.

Lastly, the third study conducted in Algiers discovered higher DDE levels in females, but no significant difference was detected for other types of POPs (11). These inconsistent associations between POPs level and gender might be caused by the unequal representation of the sample and difference of exposure among the two genders. Therefore, gender might not be 
a direct factor affecting POPs levels in the specimens studied above. It is possible to observe it as an indirect factor since women might have a pregnancy and lactating history, different body physiology, and different dietary habits compared to men (57).

There have always been gaps regarding gender in toxicology research, including the pollutant absorption and metabolism differences among both sexes. However, it can be said that both genders have different exposure, sociocultural, body size, and composition, genetic, hormonal, and reproductive system.

\section{Race/Ethnicity}

A study from Michigan, United States, discovered that African Americans had higher PCBs concentrations than Caucasians (63). On the other hand, a study from the same state discovered otherwise, which was lower PCBs concentrations among African Americans (57). A study from the United States discovered that nonHispanic individuals had higher PCB levels in serum (42). Lastly, a study from the Arctic regions discovered higher POPs (OCPs, PCBs, and PBDEs) in Inuit people than in non-Inuit people (64). Another study from the United States discovered that African Americans had a nine times greater chance of being $\geq 10$ detected with POPs at higher levels than their Caucasian counterparts (65).

No arguments were stated on how race/ethnicity could affect the POPs levels in those studies. However, differences in OCPs metabolism rates among races might be discovered (66). Different eating habits can also cause significantly different POPs levels between races. For example, Inuit people consume traditional Inuit foods that consist of fish and meat. Another study from Alabama, United States, discovered associations between race and dietary habits (66). This strengthens the possibility that race/ethnicity's impact on POPs levels in human specimens is linked with the dietary habit, making race/ethnicity an indirect factor for POPs levels.

\section{Parity}

Parity has been associated with POPs levels - especially in breast milk - in many studies where the population is nursing mothers. Only two studies discovered significant negative associations between parity and POPs levels in human specimens. The first study noticed that women with less parity, especially nulliparity, have more POPs levels in their blood and urine samples (46). A study with a cohort design discovered similar results, namely more POPs levels in nulliparous women (47). Another study discovered similar negative associations as well, however they were not statistically tested (63).

The results of this research are consistent with the theory that multipara mothers have lower POPs levels than primipara mothers (60). Multipara mothers might have lower POPs levels due to the excretion of the contaminants through multiple pregnancies (48). Lactation can also lower the POPs levels since mothers transfer the contaminants to their offspring. Infants can be exposed to POPs through the placenta and breast milk. After infants absorb POPs during pregnancy, they will be distributed in the body lipids. Subsequently, POPs in breast milk would be excreted through children's milk consumption.

Meanwhile, three studies did not discover any associations between parity and POPs level in human specimens. However, the absence of associations in the first study was not statistically tested (6). The second study did not discover any significant correlations between parity and POPs levels in breast milk. However, since no associations between POPs levels and any other mother's characteristics were discovered, the limited sample size was cited as the probable cause (39). The third study discovered no associations between the two variables and a small sample size as the probable cause (48).

\section{Dietary Habits}

It has been noted that the main source of POPs presence in the human specimens is a dietary habit (30). A total of eight studies discovered associations between dietary habits and POPs levels in human specimens, and the sample used in all those studies is breast milk. A study from China discovered that frequent consumption of meat, chicken, and dairy products is linked with OCPs presence in breast milk (14). Dairy product consumption may cause higher POPs levels due to fats contained in those products. A study from Belgium discovered that mothers who have the habit of consuming homeproduced eggs, fish, and fish oil have higher levels of DDT and DDE (9).

A study from Poland discovered higher $\beta$-Endosulfan levels in mothers who consume fish and poultry frequently (67). $\beta$-Endosulfan is an isomer of Endosulfan, an organochlorine pesticide widely used as an insecticide. Unlike other organochlorine pesticides, endosulfan is less lipophilic, causing the biomagnification and bioaccumulation process to be less likely to occur. Nonetheless, it is still possible for Endosulfan to appear 
in human specimens from fish and poultry intake since fish is highly susceptible to waterborne endosulfans (68). Endosulfan can also be present in poultry since endosulfan has a high affinity to soil (69).

A study from Spain discovered higher polychlorinated dibenzo-p-dioxins and dibenzofurans (PCDD/Fs) levels in women's breast milk who have the habit of consuming fish, meat, and oil, and fat (44). $\mathrm{PCDD} / \mathrm{Fs}$ are byproduct chemicals produced from an industrial process, such as waste incineration and smelting. However, PCDD/Fs exposure in humans is mainly from dietary intake (70). Frequent consumption of fatty foods consisting of fish, meat, fish oil, and fats can influence the breast milk profile (44), and the above five studies have proved this.

A study from Spain discovered associations between fish, fruit, meat, vegetables, and shellfish consumption and organochlorine compounds levels in serum (71). Fish and meat consumption significantly correlated with DDT levels, but the most significant food items that affected organochlorine compounds levels in the serum were fish and fruit. Since OCPs are fat-soluble, their presence in fruits and vegetables suggested using the chemicals in agriculture. OCPs residues in fruits were also observed in a study in Ghana (72).

A study from the United States discovered strong associations between dietary habits comprising of meat, dairy products, fish, and eggs and PCBs levels in normal and underweight individuals (42). A study from Poland observed that dairy products and fish consumption was significantly associated with POPs levels (30). Lastly, a study in Greenland discovered higher POPs levels in individuals who consumed traditional Greenlandic foods frequently (64).

Although dietary habit is an important risk factor affecting POPs levels in human specimens, some studies did not discover correlations between these two variables. A study from Jordan stated that there were no associations between dietary habits and POPs levels in the breast milk of 100 mothers, but there was a high probability that they were not statistically tested (6). A study conducted in China also failed to discover a significant correlation between dietary habits and OCPs concentration in human milk, with the varying sources of OCPs and not only from a particular source was cited as the probable cause (39). An article that studied PBBs body burden on Michigan residents who were victims of Michigan's PBB incident discovered that residents who consumed PBBs-contaminated food products had higher PBBs levels in their serum, but they were not significant (57). In a study from Brazil, milk and meat consumption were not significantly associated with OCPs levels in breast milk; however, a limited sample size was cited as the probable cause (49).

Overall, dietary habit is a plausible and strong determinant that can affect POPs levels in human specimens, even though there are articles that did not discover any correlations between dietary habits and POPs levels. Moreover, the studies that did not discover correlations had reasonable limitations, causing the absence of correlations between the two variables.

\section{Physical Activities}

A study from South Korea observed correlations between decreasing OCPs levels $\left(\beta-\mathrm{HCH}, \mathrm{p}, \mathrm{p}^{\prime}-\mathrm{DDT}\right.$, and $\left.p, p^{\prime}-D D E\right)$ in serum with increasing physical activity duration $(p<0,01)$, although no associations were observed between physical activities and PCBs levels (45). A similar study from Europe (58) also discovered no association between physical activities and the amount PCB levels. Although physical activities were not associated with PCB levels in the two studies, OCPs were significantly associated. Increasing physical activities might result in lower BMI and lower body fatness, hence lower OCPs levels in the serum.

\section{Smoking Status}

Studies on the relationship between smoking status and POPs levels in human specimens have been inconsistent. Four studies in Table 2 discovered associations between smoking status and POPs level in blood and urine samples. Surprisingly, two of those studies observed lower POPs levels in current smokers than in non-smoker and former smokers. The first study discovered higher OCPs concentration in non-smokers (47), whereas the second study from the United States discovered more decreasing PBB concentration in the serum of current smokers than in those who never smoked (57).

Two studies noticed higher POPs levels in individuals who used to smoke. In the first study, the percentage of women with the extreme value of POPs is higher in groups who halted smoking during pregnancy than in non-smokers and former smokers group (46). The second study discovered significantly higher PCBs concentrations in former smokers than participants who never smoked (73). Enzymes from the cytochromes P450 (CYPs) oxidase system were cited as the cause. CYPs are enzymes that play a role in chemical or pollutant detoxification and activation. Higher POPs levels in serum might result from POPs and nicotine metabolism by CYPs (73). 


\section{Residency (Urban/Rural)}

Only two articles examined the POPs levels between individuals who live in an urban and rural area, as indicated in Table 2. The first study conducted in Belgium noticed that mothers in rural areas had higher DDT and DDE levels in their breast milk (9). However, a study from China did not discover any associations between these two variables (39).

Individuals from rural areas might have higher POPs concentration than those living in urban areas due to POPs exposure to agricultural activities. Individual dietary habits and activities can also result in higher exposure to POPs (74). This is in line with a result from a study in Indonesia, where mothers who live in rural areas have the habit of consuming fish from rivers where farmers wash their OCPs-contaminated farming equipment (60). Although residency is often studied for its association with POPs levels, the results were largely inconsistent.

\section{Emissions from Industry}

It has been well observed that there are unintentionally produced POPs from industrial processes released into the environment. $\mathrm{HCB}$ and polycyclic aromatic hydrocarbons (PAH) are two POPs mostly produced by industrial processes, at $44.8 \%$ and $51.9 \%$, respectively. Even though POPs emission from industrial processes and product use have decreased by $83 \%$ since 1990 (75), biomonitoring studies still need to be conducted due to significant POPs exposure through inhaling contaminated air near waste recycling sites and landfills (5).

A recent study from China discovered that the source of polychlorinated naphthalenes (PCNs) contamination in breast milk was large electronic waste recycling activities (76). PCNs were used as fire retardants in consumer goods and considered POPs in 2015. PCNs presence in breast milk near the waste incineration produced ash, particulate, pollutants, and toxic POPs, including PCNs (29). A similar study from Pakistan also discovered high PCNs levels in the dust sample of recycling hubs. They also observed higher PCNs levels in the serum of e-waste workers than in regular residents and children (10). These results indicate that the waste recycling process can affect the POPs levels in the human specimens.

\section{Household Dust}

Besides diet, lactation, and utero transmission, exposure to PBDEs through inhalation of polluted indoor and outdoor air can also occur in humans (77-78). A study from Alaska, United States, noticed statistical correlations between PBDEs concentration in serum and household dust exposure (79). PBDEs are often used as fire retardants in commercial products, for instance, furniture, electronics, and plastics (80). There also have been several studies that discovered air contaminated with PBDEs from those commercial products (81), asserting the possibility that household dust can affect POPs levels in human specimens.

\section{CONCLUSION}

Out of 28 articles, $61 \%$ detected POPs presence in the blood (serum or plasma), $39 \%$ in breast milk, $14 \%$ in urine, and $10 \%$ in hair samples. Each determinant cannot individually affect the POPs levels in the human specimens since those determinants affect each other. Further studies on this topic using a systematic literature review are recommended to provide more reliable results.

\section{REFERENCES}

1. Tiwari M, Sahu SK, Pandit GG. Distribution and Ecotoxicological Concerns of Persistent Organic Pollutants in Sediment from Creek Ecosystem. Journal of Environmental Science and Health, Part B. 2016;51(9):616-621. https://doi.org/10.1080/03 $\underline{601234.2016 .1181907}$

2. Nežiková B, Degrendele $C$, Čupr P, Hohenblum P, Moche W, Prokeš R, et al. Bulk Atmospheric Deposition of Persistent Organic Pollutants and Polycyclic Aromatic Hydrocarbons in Central Europe. Environmental Science and Pollution Research. 2019;26(23):23429-23441. https://doi. org/10.1007/s11356-019-05464-9

3. Choo G, Wang W, Cho HS, Kim K, Park K, Oh JE. Legacy and Emerging Persistent Organic Pollutants in the Freshwater System: Relative Distribution, Contamination Trends, and Bioaccumulation. Environment International. 2020;135(105377):1-8. https://doi.org/10.1016/j.envint.2019.105377

4. Ashraf MA. Persistent Organic Pollutants (POPs): A Global Issue, A Global Challenge. Environmental Science and Pollution Research. 2017;24(5):42234227. https://doi.org/10.1007/s11356-015-5225-9

5. Agency for Toxic Substances and Disease Registry. Toxicological for DDT/DDE/DDD (Update). Atlanta, GA: U.S. Department of Health and Human Services, Public Health Service. 2002. http://www. atsdr.cdc.gov/toxfaqs/index.asp

6. Al Antary TM, Alawi MA, Estityah H, Haddad N. Organochlorine Pesticides Residues in Human Breast Milk from the Middle Governorates in Jordan in 2013/2014. Bulletin of Environmental Contamination and Toxicology. 2017;99(1):89-92. https://doi.org/10.1007/s00128-017-2117-3

7. Islam R, Kumar S, Karmoker J, Kamruzzaman M, Rahman MA, Biswas N, et al. Bioaccumulation and Adverse Effects of Persistent Organic Pollutants (POPs) On Ecosystems and Human Exposure: 
A Review Study on Bangladesh Perspectives. Environmental Technology \& Innovation. 2018;12(1):115-131. $\quad$ https://doi.org/10.1016/j. eti.2018.08.002

8. Fry K, Power MC. Persistent Organic Pollutants and Mortality in the United States, NHANES 19992011. Environmental Health. 2017;16(105):1-12. https://doi.org/10.1186/s12940-017-0313-6

9. Aerts R, Van Overmeire I, Colles A, Andjelković M, Malarvannan G, Poma G, et al. Determinants of Persistent Organic Pollutant (POP) Concentrations in Human Breast Milk of a Cross-Sectional Sample of Primiparous Mothers in Belgium. Environment International. 2019;131(104979):1-10. https://doi. org/10.1016/j.envint.2019.104979

10. Waheed S, Khan MU, Sweetman AJ, Jones KC, Moon HB, Malik RN. Exposure of Polychlorinated Naphthalenes (PCNs) To Pakistani Populations via Non-Dietary Sources From Neglected E-Waste Hubs: A Problem of High Health Concern. Environmental Pollution. 2020;259:113838. https:// doi.org/10.1016/i.envpol.2019.113838

11. Mansouri EH, Reggabi M. Plasma Concentrations of Chlorinated Persistent Organic Pollutants and Their Predictors in the General Population of Algiers, Algeria. Emerging Contaminants. 2021;7:35-42. https://doi.org/10.1016/j.emcon.2020.12.003

12. Trejo-Acevedo A, Rivero-Pérez NE, Flores-Ramírez $\mathrm{R}$, Sandra, Orta-García T, José, et al. Assessment of the Levels of Persistent Organic Pollutants and 1-Hydroxypyrene in Blood and Urine Samples from Mexican Children Living in an Endemic Malaria Area in Mexico. Bulletin of Environmental Contamination and Toxicology. 2012;88(6):828-832. https://doi. org/10.1007/s00128-012-0593-z

13. Junqué $E$, Garí $M$, Arce $A$, Torrent $M$, Sunyer J, Grimalt JO. Integrated Assessment of Infant Exposure to Persistent Organic Pollutants and Mercury via Dietary Intake in a Central Western Mediterranean Site (Menorca Island). Environmental Research. 2017;156(1):714-24. https://10.0.3.248/j.envres.2017.04.030

14. Chen MW, Santos HM, Que DE, Gou YY, Tayo LL, Hsu YC, et al. Association Between Organochlorine Pesticide Levels in Breast Milk and Their Effects on Female Reproduction in a Taiwanese Population. International Journal of Environmental Research and Public Health. 2018;15(5):1-22. https://doi. org/10.3390/ijerph15050931

15. United Nations Environment Programme. Listing of POPs in the Stockholm Convention. Switzerland: United Nations Environment Programme. 2021. http://chm.pops.int/TheConvention/ThePOPs/ ListingofPOPs/tabid/2509/Default.aspx

16. United Nations Environment Programme. Stockholm Convention Protecting Human Health and Environment from Persistent Organic Pollutants. Switzerland: United Nations Environment Programme. 2019. http://www.pops.int

17. World Health Organization. Global Insecticide Use for Vector-Borne Disease Control: A 10-year Assessment (2000-2009). 5th ed. Geneva: World Health Organization Press; 2011.
18. Jiang X, Liu G, Wang M, Zheng M. Formation of Polychlorinated Biphenyls on Secondary Copper Production Fly Ash: Mechanistic Aspects and Correlation to Other Persistent Organic Pollutants. Scientific Reports. 2015;5(1):1-10. https://doi. org/10.1038/srep13903

19. United Nations Environment Programme. Guidance for The Inventory of Polybrominated Diphenyls (PBDEs) Listed Under the Stockholm Convention on Persistent Organic Pollutants. 2012. Switzerland: United Nations Environment Programme. 1-129 p. http://sib3pop.menlhk.go.id/uploads/Regulasi/ UNEP-POPS-GUID-NIP-2012-PBDEs-Inventory. En.pdf

20. Environmental Protection Agency. Persistent Organic Pollutants: A Global Issue, A Global Response | US EPA. United States: Environmental Protection Agency; 2009. https://www.epa.gov/ international-cooperation/persistent-organicpollutants-global-issue-global-response\#affect

21. Rahman ML, Zhang C, Smarr MM, Lee S, Honda M, Kannan K, et al. Persistent Organic Pollutants and Gestational Diabetes: A Multi-Center Prospective Cohort Study of Healthy US Women. Environment International. 2019;124(1):249-258. https://doi. org/10.1016/j.envint.2019.01.027

22. Wolf $K$, Bongaerts BWC, Schneider A, Huth $C$, Meisinger $C$, Peters A, et al. Persistent Organic Pollutants and the Incidence of Type 2 Diabetes in the CARLA and KORA Cohort Studies. Environment International. 2019;129(1):221-228. https://doi. org/10.1016/j.envint.2019.05.030

23. Zong G, Valvi D, Coull B, Göen T, Hu FB, Nielsen F, et al. Persistent Organic Pollutants and Risk of Type 2 Diabetes: A Prospective Investigation Among Middle-Aged Women in Nurses' Health Study II. Environment International. 2018;114(1):334-342. https://doi.org/10.1016/j.envint.2017.12.010

24. Koual M, Cano-Sancho G, Bats AS, Tomkiewicz C, Kaddouch-Amar $\mathrm{Y}$, Douay-Hauser $\mathrm{N}$, et al. Associations Between Persistent Organic Pollutants and Risk of Breast Cancer Metastasis. Environment International. 2019;132(105028):1-10. https://doi. org/10.1016/j.envint.2019.105028

25. Wielsøe M, Kern P, Bonefeld-Jørgensen EC. Serum Levels of Environmental Pollutants is a Risk Factor for Breast Cancer in Inuit: A Case Control Study. Environmental Health: A Global Access Science Source. 2017;16(56):1-16. https://doi.org/10.1186/ s12940-017-0269-6

26. Gupta P, Thompson BL, Wahlang B, Jordan CT, Hilt JZ, Hennig B, et al. The Environmental Pollutant, Polychlorinated Biphenyls, and Cardiovascular Disease: A Potential Target for Antioxidant Nanotherapeutics. Drug Delivery and Translational Research. 2018;8(3):740-759. https://doi. org/10.1007/s13346-017-0429-9

27. Coole JB, Burr SS, Kay AM, Singh JA, Kondakala S, Yang EJ, et al. Persistent Organic Pollutants (POPs) Increase Rage Signaling to Promote Downstream Cardiovascular Remodeling. Environmental Toxicology. 2019;34(10):1149-1159. https://doi. org/10.1002/tox.22817 
28. Gregoraszczuk EL, Ptak A. Endocrinedisrupting Chemicals: Some Actions of POPs on Female Reproduction. International Journal of Endocrinology. 2013;2013(828532):1-10. https:// doi.org/10.1155/2013/828532

29. Li C, Yang L, Liu X, Yang Y, Qin L, Li D, et al. Bridging the Energy Benefit and POPs Emission Risk from Waste Incineration. The Innovation. 2021;2(1):1-7. https://doi.org/10.1016/j.xinn.2020.100075

30. Grešner P, Zieliński M, Ligocka D, Polańska K, Wąsowicz W, Gromadzińska J. Environmental Exposure to Persistent Organic Pollutants Measured in Breast Milk of Lactating Women From an Urban Area in Central Poland. Environmental Science and Pollution Research. 2021;28(4):4549-4557. https:// doi.org/10.1007/s11356-020-10767-3

31. Lenters V, Iszatt N, Forns J, Čechová E, Kočan A, Legler J, et al. Early-Life Exposure to Persistent Organic Pollutants (OCPs, PBDEs, PCBs, PFASs) and Attention-Deficit/Hyperactivity Disorder: A MultiPollutant Analysis of a Norwegian Birth Cohort. Environment International. 2019;125(1):33-42. https://doi.org/10.1016/j.envint.2019.01.020

32. Berg V, Nøst TH, Pettersen RD, Hansen S, Veyhe AS, Jorde R, et al. Persistent Organic Pollutants and the Association With Maternal and Infant Thyroid Homeostasis: A Multipollutant Assessment. Environ Health Perspect. 2017;125(1):127-133. https://doi. org/10.1289/EHP152

33. Bell GA, Perkins N, Buck Louis GM, Kannan K, Bell EM, Gao C, et al. Exposure to Persistent Organic Pollutants and Birth Characteristics: The Upstate KIDS Study. Epidemiology. 2019;30(Suppl 2):S94-100. https://doi.org/10.1097/ EDE.0000000000001095

34. Lauritzen HB, Larose $T L$, Øien $T$, Sandanger TM, Odland JO, Van De Bor M, et al. Prenatal Exposure to Persistent Organic Pollutants and Child Overweight/Obesity at 5-Year Follow-Up: A Prospective Cohort Study. Environmental Health. 2018;17(9):1-12. https://doi.org/10.1186/s12940017-0338-x

35. Wang S, Hu C, Lu A, Wang Y, Cao L, Wu W, et al. AssociationBetweenPrenatalExposuretoPersistent Organic Pollutants and Neurodevelopment in Early Life: A Mother-Child Cohort (Shanghai, China). Ecotoxicology and Environmental Safety. 2021;208(111479):1-8. https://doi.org/10.1016/j. ecoenv.2020.111479

36. Kao CC, Que DE, Bongo SJ, Tayo LL, Lin YH, Lin CW, et al. Residue Levels of Organochlorine Pesticides in Breast Milk and Its Associations With Cord Blood Thyroid Hormones and the Offspring's Neurodevelopment. International Journal of Environmental Research and Public Health. 2019;16(8):1-19. https://doi.org/10.3390/ ijerph16081438

37. Carvalho DFP, Meire RO, Guimarães MT, Pereira LAA, Braga ALF, Bernardo RR, et al. Determination of Environmental Exposure to DDT by Human Hair Analysis in Santos and São Vicente Estuary,
São Paulo, Brazil. Orbital. 2018;10(4 Special Issue):308-319. https://doi.org/10.17807/orbital. v10i4.1089

38. Müller MHB, Polder A, Brynildsrud OB, Karimi M, Lie E, Manyilizu WB, et al. Organochlorine Pesticides (OCPs) and Polychlorinated Biphenyls (PCBs) In Human Breast Milk and Associated Health Risks to Nursing Infants in Northern Tanzania. Environmental Research. 2017;154(1):425-434. http://dx.doi.org/10.1016/j.envres.2017.01.031

39. Kuang L, Hou Y, Huang F, Guo A, Deng W, Sun $\mathrm{H}$, et al. Pesticides in Human Milk Collected From Jinhua, China: Levels, Influencing Factors and Health Risk Assessment. Ecotoxicology and Environmental Safety. 2020;205(111331):1-8. https://doi.org/10.1016/j.ecoenv.2020.111331

40. Iglesias-González A, Hardy EM, Appenzeller BMR. Cumulative Exposure to Organic Pollutants of French Children Assessed by Hair Analysis. Environment International. 2020;134(105332):116. https://doi.org/10.1016/j.envint.2019.105332

41. Peng FJ, Emond C, Hardy EM, Sauvageot $N$, Alkerwi A, Lair ML, et al. Population-Based Biomonitoring of Exposure to Persistent and Non-Persistent Organic Pollutants in the Grand Duchy of Luxembourg: Results from Hair Analysis. Environment International. 2021;153(106526):1-11. https://doi.org/10.1016/j.envint.2021.106526

42. Lan T, Liu B, Bao W, Thorne PS. BMI Modifies the Association Between Dietary Intake and Serum Levels of PCBs. Environment International. 2021;156(106626):1-9. https://doi.org/10.1016/j. envint.2021.106626

43. Fiedler $\mathrm{H}$, Kallenborn $\mathrm{R}$, Boer $\mathrm{J}$ de, Sydnes LK. The Stockholm Convention: A Tool for the Global Regulation of Persistent Organic Pollutants. Chemistry International. 2019;41(2):4-11. https:// www.degruyter.com/document/doi/10.1515/ci2019-0202/html

44. Schuhmacher M, Mari M, Nadal M, Domingo JL. Concentrations of Dioxins and Furans in Breast Milk of Women Living Near a Hazardous Waste Incinerator in Catalonia, Spain. Environment International. 2019;125(1):334-341. https://doi. org/10.1016/j.envint.2019.01.074

45. Lee YM, Shin JY, Kim SA, Jacobs DR, Lee DH. Can Habitual Exercise Help Reduce Serum Concentrations of Lipophilic Chemical Mixtures? Association Between PhysicalActivity and Persistent Organic Pollutants. Diabetes \& Metabolism Journal. 2020;44(1):764-774. $\quad$ https://doi.org/10.4093/ dmj.2019.0158

46. Lee WC, Fisher M, Davis K, Arbuckle TE, Sinha SK. Identification of Chemical Mixtures to Which Canadian Pregnant Women Are Exposed: The MIREC Study. Environment International. 2017;99(1):321-330. http://dx.doi.org/10.1016/j. envint.2016.12.015

47. Lewin A, Arbuckle TE, Fisher M, Liang CL, Marro L, Davis K, et al. Univariate Predictors of Maternal Concentrations of Environmental Chemicals: The 
MIREC Study. International Journal of Hygiene and Environmental Health. 2017;220(2):77-85. http:// dx.doi.org/10.1016/j.ijheh.2017.01.001

48. Du J, Gridneva Z, Gay MCL, Lai CT, Trengove RD, Hartmann PE, et al. Longitudinal Study of Pesticide Residue Levels in Human Milk From Western Australia During 12 Months of Lactation: Exposure Assessment for Infants. Sci Rep. 2016;6(1):1-11. http://dx.doi.org/10.1038/srep38355

49. Souza RC, Portella RB, Almeida PVNB, Pinto CO, Gubert P, Santos da Silva JD, et al. Human Milk Contamination by Nine Organochlorine Pesticide Residues (OCPs). Journal of Environmental Science and Health, Part B, Pesticides, Food Contaminants, and Agricultural Wastes. 2020;55(6):530-538. https://doi.org/10.1080/03601234.2020.1729630

50. World Health Organization. The Use of DDT in Malaria Vector Control WHO Position Statement. Geneva: World Health Organization; 2007. http://www.who.int/ipcs/capacity building/who statement.pdf

51. Agency for Toxic Substances and Disease Registry. Hexachlorocyclohexane $(\mathrm{HCH})$ | Toxic Substances | Toxic Substance Portal. Atlanta: United States Department of Health and Human Services Public Health Service; 2021. https://wwwn.cdc.gov/TSP/ substances/ToxSubstance. aspx?toxid $=138$

52. Environment Protection Agency. Hexachlorobenzene. United States: Environmental Protection Agency; 2016. https://www.epa. gov/sites/production/files/2016-09/documents/ hexachlorobenzene.pdf

53. Wahlang B. Exposure to Persistent Organic Pollutants: Impact on Women's Health. Reviews on Environmental Health. 2018;33(4):331-348. https:// doi.org/10.1515/reveh-2018-0018

54. Enviroforensics. What are Polychlorinated Biphenyls (PCBs)?. Wilmington: Enviroforensics; 2021. https://www.enviroforensics.com/blog/whatare-polychlorinated-biphenyls-pcbs/

55. Fernández-Rodríguez M, Arrebola JP, ArtachoCordón F, Amaya E, Aragones N, Llorca J, et al. Levels and Predictors of Persistent Organic Pollutants in an Adult Population From Four Spanish Regions. Science of the Total Environment. 2015;538(1):152-161. http://dx.doi.org/10.1016/j. scitotenv.2015.07.162

56. Vrijheid M, Fossati S, Maitre L, Márquez S, Roumeliotaki T, Agier L, et al. Early-life Environmental Exposures and Childhood Obesity: An Exposome-wide Approach. Environmental Health Perspectives. 2020;128(6):1-14. https://doi. org/10.1289/EHP5975

57. Chang CJ, Terrell ML, Marcus M, Marder ME, Panuwet P, Ryan PB, et al. Serum Concentrations of Polybrominated Biphenyls (PBBs), Polychlorinated Biphenyls (PCBs) and Polybrominated Diphenyl Ethers (PBDEs) In the Michigan PBB Registry 40 Years After the PBB Contamination Incident. Environment International. 2020;137(105526):112. https://doi.org/10.1016/j.envint.2020.105526
58. Domazet SL, Grøntved A, Jensen TK, Wedderkopp $\mathrm{N}$, Andersen LB. Higher Circulating Plasma Polychlorinated Biphenyls (PCBs) in Fit and Lean Children: The European Youth Heart Study. Environment International. 2020;136(105481):1-8. https://doi.org/10.1016/j.envint.2020.105481

59. Güil-Oumrait N, Valvi D, Garcia-Esteban R, Guxens M, Sunyer J, Torrent M, et al. Prenatal Exposure to Persistent Organic Pollutants and Markers of Obesity and Cardiometabolic Risk in Spanish Adolescents. Environment International. 2021;151(106469):1-12. https://doi.org/10.1016/j. envint.2021.106469

60. Cahyaningrum D, Denny HM, Adi MS. Kandungan Pestisida Organoklorin dalam Air Susu lbu di Daerah Pertanian Bawang Merah Kabupaten Brebes. Jurnal Promosi Kesehatan Indonesia. 2018;13(1):32-45. https://doi.org/10.14710/jpki.13.1.32-45

61. Barrett JR. POPs vs. Fat Persistent Organic Pollutant Toxicity Targets and is Modulated by Adipose Tissue. Environmental Health Perspectives. 2013;121(2):a61. https://doi.org/10.1289/ehp.121a61

62. Soleman SR, Fujitani T, Fujii Y, Harada KH. Levels of Octachlorostyrene in Mothers' Milk and Potential Exposure Among Infants in Sendai City, Japan 2012. International Journal of Environmental Research and Public Health. 2020;17(9):1-10. https://doi. org/10.3390/ijerph17093064

63. Wattigney WA, Irvin-Barnwell E, Li Z, RaginWilson A. Biomonitoring of Mercury and Persistent Organic Pollutants in Michigan Urban Anglers and Association With Fish Consumption. International Journal of Hygiene and Environmental Health. 2019;222(6):936-944. https://doi.org/10.1016/j. ijheh.2019.06.007

64. Schæbel LK, Bonefeld-Jørgensen EC, Vestergaard $\mathrm{H}$, Andersen S. The Influence of Persistent Organic Pollutants in the Traditional Inuit Diet on Markers of Inflammation. PLoS One. 2017;12(5):1-16. https:// doi.org/10.1371/journal.pone.0177781

65. Pumarega J, Gasull M, Lee D-H, López T, Porta M. Number of Persistent Organic Pollutants Detected at High Concentrations in Blood Samples of the United States Population. PLoS One. 2016;11(8):116. https://doi.org/10.1371/journal.pone.0160432

66. Aminov Z, Haase R, Olson JR, Pavuk M, Carpenter DO, Bartell S, et al. Racial Differences in Levels of Serum Lipids and Effects of Exposure to Persistent Organic Pollutants on Lipid Levels in Residents of Anniston, Alabama. Environment International. 2014;73(1):216-223. http://dx.doi.org/10.1016/j. envint.2014.07.022

67. Witczak A, Pohoryło A, Abdel-Gawad H. EndocrineDisrupting Organochlorine Pesticides in Human Breast Milk: Changes During Lactation. Nutrients. 2021;13(1):1-19. $\quad$ https://doi.org/10.3390/ nu13010229

68. Berntssen MHG, Maage A, Lundebye A-K. Chapter 20 - Chemical Contamination of Finfish With Organic Pollutants and Metals. Cambridge: Woodhead 
Publishing Series in Food Science, Technology and Nutrition; 2017. https://doi.org/10.1016/B978-0-08100674-0.00020-5

69. Singh P, Volger B, Gordon E. Endosulfan. Oxford: Academic Press; 2014. https://www.sciencedirect. com/science/article/pii/B978012386454300141X

70. Marquès $\mathrm{M}$, Domingo JL. Concentrations of $\mathrm{PCDD} /$ Fs in Human Blood:AReview of Data from the Current Decade. International Journal of Environmental Research and Public Health. 2019;16(19):1-18. https://doi.org/10.3390/ijerph16193566

71. Junqué E, Garí M, Llull RM, Grimalt JO. Drivers of the Accumulation of Mercury and Organochlorine Pollutants in Mediterranean Lean Fish and Dietary Significance. Science of the Total Environment. 2018;634(1):170-180. https://doi.org/10.1016/j. scitotenv.2018.03.335

72. Forkuoh F, Boadi NO, Borquaye LS, Afful S. Risk Of Human Dietary Exposure to Organochlorine Pesticide Residues in Fruits from Ghana. Scientific Reports. 2018;8(1):1-5. http://dx.doi.org/10.1038/ s41598-018-35205-w

73. Moon HJ, Lim JE, Jee SH. Association Between Serum Concentrations of Persistent Organic Pollutants and Smoking in Koreans: A CrossSectional Study. Journal of Epidemiology. 2017;27(2):63-68. http://dx.doi.org/10.1016/j. 迆.2016.09.006

74. Luzardo OP, Badea M, Zumbado M, Rogozea $L$, Floroian L, llea $A$, et al. Body Burden of Organohalogenated Pollutants and Polycyclic Aromatic Hydrocarbons in Romanian Population: Influence of Age, Gender, Body Mass Index, and Habitat. Science of the Total Environment. 2019;656(1):709-716. https://doi.org/10.1016/j. scitotenv.2018.11.404

75. European Environment Agency. Persistent Organic Pollutant Emissions. Copenhagen: European Environment Agency; 2021. https://www.eea. europa.eu/data-and-maps/indicators/eea32persistent-organic-pollutant-pop-emissions-1/ assessment-10
76. Li C, Zhang L, Li J, Min Y, Yang L, Zheng M, et al. Polychlorinated Naphthalenes in Human Milk: Health Risk Assessment to Nursing Infants and Source Analysis. Environment International. 2020;136(105436):1-8. $\quad$ https://doi.org/10.1016/j. envint.2019.105436

77. Fromme H, Becher G, Hilger B, VölkelW. Brominated Flame Retardants - Exposure and Risk Assessment for the General Population. International Journal of Hygiene and Environmental Health. 2016;219(1):123. https://doi.org/10.1016/j.ijheh.2015.08.004

78. Genuis SK, Birkholz D, Genuis SJ. Human Excretion of Polybrominated Diphenyl Ether Flame Retardants: Blood, Urine, and Sweat Study. Biomed Research International. 2017;2017(3676089):1-14. https://doi.org/10.1155/2017/3676089

79. Byrne S, Seguinot-Medina S, Miller P, Waghiyi $V$, Hippel FA von, Buck CL, et al. Exposure to Polybrominated Diphenyl Ethers and Perfluoroalkyl SubstancesinaRemotePopulationofAlaskaNatives. Environmental Pollution. 2017;231(Pt 1):387-395. https://doi.org/10.1016/j.envpol.2017.08.020

80. Environment Protection Agency. Polybrominated diphenylethers (PBDEs) Significant New Use Rules (SNUR). Washington DC: Environment Protection Agency; 2021. https://www.epa.gov/assessing-andmanaging-chemicals-under-tsca/polybrominateddiphenylethers-pbdes-significant-new-use

81. Giovanoulis G, Nguyen MA, Arwidsson M, Langer $S$, Vestergren R, Lagerqvist A. Reduction of Hazardous Chemicals in Swedish Preschool Dust Through Article Substitution Actions. Environment International. 2019;130(104921):1-11. https://doi. org/10.1016/j.envint.2019.104921

82. Fiedler H, Sadia M. Regional Occurrence of Perfluoroalkane Substances in Human Milk for the Global Monitoring Plan Under the Stockholm Convention on Persistent Organic Pollutants During 2016-2019. Chemosphere. 2021;277(130287):1-9. https://doi.org/10.1016/j. chemosphere.2021.130287 